\title{
Under the Cover of Night: Abortion Across Borders
}

\author{
Carmen Landau MD and Lisa Long BS
}

Jessica and Robert* had a three-year-old son and were excited about their second child, a daughter. When Jessica was 21 weeks pregnant, the routine ultrasound was normal. At 26 weeks, she was in a minor car accident and her obstetrician referred her for a specialized ultrasound, concerned about the baby's heart. This was how Jessica and Robert discovered that their daughter had a serious heart defect. After meeting with a perinatologist, a genetics counselor and a pediatric cardiologist, they realized the prognosis was dire. After birth, their daughter would need urgent open-heart surgery, and would need two more surgeries in her first year of life. If she survived long enough, her only real chance would be a heart transplant. They cried, they raged, and then they turned to the Internet. They felt the only way they could protect their daughter from a lifetime of suffering was to terminate the pregnancy. When they arrived at our clinic in New Mexico, they looked beaten down, fragile. "I feel like we snuck across state borders under the cover of night," Jessica told us, "but what choice did we have?"

At 19, Dolores left Guatemala to escape brutal violence in her hometown. She and another woman traveled by foot to the USA and were raped along the way. They finally made it to a Houston shelter. But when Dolores noticed her abdomen swelling, she thought she had a tumor. She had no memory of the rape, having blocked out the unbearable trauma, and knew little about the workings of her body. Finally, she discovered she was pregnant and, according to state law, too far along to have an abortion in Texas. A shelter volunteer helped her make an appointment at our clinic.

Dolores reached us with a driver from the shelter, who she had never met. Traveling 13 hours to Albuquerque with a strange man, however well-intentioned, added nearly overwhelming stress. Unfamiliar with interstate travel and the law, she also feared she would be arrested at the state border and deported. After her abortion, she literally got down on her knees and thanked us, admitting she had planned to kill herself if she couldn't access an abortion.

We are fortunate in New Mexico, where no strict gestational age restriction has been legislated. This grants women the agency to make complex decisions regarding their pregnancies, based exclusively on their personal ethics and medical expert opinions, including safety. Only about $1 \%$ of abortions in the USA are performed after 20 weeks, and the data show women in New Mexico do not make later decisions to terminate their pregnancies. But when complex situations arise, they can access care in their own state. New Mexico is also one of only 17 states in which Medicaid pays for abortion, making services accessible for most residents, no matter their financial situation.

We are struck by the stories of women like Jessica and Dolores, who have little in common besides a legal abortion denied near home. Jessica had the financial means to get to New Mexico and supportive people by her side; the education and access to information that allowed her to learn about the option of abortion under safe and legal conditions, overcoming her home-state restrictions. Dolores was desperate and just happened to be lucky enough to find help, otherwise committed to ending her own life. Abortion is a reality for women in the United States: one in three will have one in her lifetime. Making abortion illegal or highly restricted has not been shown to reduce a country's abortion rate, but instead puts women at increased risk for the harm associated with unsafe abortion. In fact, when abortion is illegal or highly restricted, consequences can be severe and dangerous.

First, women who must travel far for the procedure often do not access care until later in their pregnancy. This not only results in a higher-risk procedure, but also creates greater emotional burdens. Second, restrictive laws overwhelmingly affect poor women.[1] Those who manage to seek abortions elsewhere are less likely to have them covered by insurance and more likely to suffer increased financial strain associated with the procedure, as well as with travel, lodging, lost wages or employment. What's more, data from the Turnaway Study show that women who had a baby after being denied an abortion due to local gestational age limits were more likely to suffer from poverty, unemployment and domestic abuse, plus higher rates of health problems such as hypertension.[1-3]

A host of intangible costs are also reported to us by out-of-state patients, over half of whom live below federal poverty levels. They report leaving their children with people they don't trust or selling important possessions such as the family car or their wedding ring. A few even admit to providing sex for the money to pay abortion costs. Travel makes it harder to keep their decision private and can place them at greater risk of violence from abusive partners. They also talk about the social stigma surrounding abortion, intensified when they are denied abortion by the same hometown doctors who provide the rest of their medical care.

For girls and women traveling outside their home country or state, the experience of a border crossing is marked by fear, despite the fact that they are committing no crime. Many women like Jessica and Dolores tell us that they were terrified to make the trip.

For a lucky few of us, border crossings are a thing of pleasure, adventure and even romance. But for much of the world's population, crossing a border is an act of despair, fleeing violence, persecution and poverty - or searching for medical care denied at home. Restrictive abortion laws in many US states and countries force women into these "ranks of the desperate," endanger their lives and violate their rights. Why must they pay such a price? - $/$ M

*Names have been changed to protect patient privacy.

1. Roberts SC, Biggs MA, Chibber KS, Gould H, Rocca CH, Foster DG. Risk of violence from the man involved in the pregnancy after receiving or being denied an abortion. BMC Med. 2014 Sep 29;12:144.

2. Harris LF, Roberts SC, Biggs MA, Rocca CH, Foster DG. Perceived stress and emotional social support among women who are denied or receive abortions in the United States: a prospective cohort study. BMC Womens Health. 2014 Jun 19;14:76.

3. Upadhyay UD, Weitz TA, Jones RK, Barar RE, Foster DG. Denial of abortion because of provider gestational age limits in the United States. Am J Public Health. 2014 Sep;104(9):1687-94.

Submitted: July 30, 2015

Approved for publication: August 25, 2015

Disclosures: None

Correspondence: carmlandau@gmail.com 